\title{
Power and Energy Visualization for the Micro-management of Household Electricity Consumption
}

Paul Monigatti

\author{
Paul Monigatt \\ (1) \\ pwm2@cs.waikato.ac.nz
}

\author{
Mark Apperley \\ University of Waikato \\ Hamilton \\ New Zealand \\ +6478384528 \\ Bill Rogers
}

m.apperley@cs.waikato.ac.nz coms0108@cs.waikato.ac.nz

\begin{abstract}
The paper describes a pilot system for the detailed management of domestic electricity consumption aimed at minimizing demand peaks and consumer cost. Management decisions are made both interactively by consumers themselves, and where practical, automatically by computer. These decisions are based on realtime pricing and availability information, as well as current and historic usage data. The benefits of the energy strategies implied by such a system are elaborated, showing the potential for significant peak demand reduction and slowing of the need for growth in generation capacity. An overview is provided of the component technologies and interaction methods we have designed, but the paper focuses on the communication of real-time information to the consumer through a combination of specific and ambient visualizations. There is a need for both overview information (eg how much power is being used right now; how much energy have we used so far today; what does it cost?) and information at the point-of-use (is it OK to turn this dryer on now, or should I wait until later?). To assist the design of these visualizations, a survey is underway aimed at establishing people's understanding of power and energy concepts.
\end{abstract}

\section{Categories and Subject Descriptors}

H.5.2 [User Interfaces]: Graphical user interfaces (GUI)

\section{General Terms}

Management, Measurement, Human Factors

\section{Keywords}

demand-side load management, information visualization, ambient visualization, domestic technology, domestic energy consumption

Permission to make digital or hard copies of all or part of this work for personal or classroom use is granted without fee provided that copies are not made or distributed for profit or commercial advantage and that copies bear this notice and the full citation on the first page. To copy otherwise, to republish, to post on servers or to redistribute to lists, requires prior specific permission and/or a fee.

AVI '10, May 25-29, 2010, Rome, Italy

Copyright $(9) 2010$ ACM 978-1-4503-0076-6/10/05 ... \$10.00

\section{INTRODUCTION}

It is contended that significant reduction in peak domestic electricity consumption, and improvements in the efficiency of this consumption, can be achieved through informed consumer load management, a mix of automated pre-programmed and personal decisions. By closely linking this demand-side management with supply-side load control and manipulation (availability and pricing), it is contended that such provisions have the potential not only to reduce the peak domestic demands for electricity now, but allow for better integration of non-carbon based generation capacity, and a slowing of the need for growth of generation capacity into the future. The Informed Demand-Side Load Management project (IDSLM) [1] is exploring the potential of these provisions.

Typical domestic electricity usage in developed countries accounts for approximately $33 \%$ of the total annual electricity consumption (for example $[6,7]$ ), and is predicted to continue to grow [7]. A significant proportion of the domestic demand is discretionary in time - for example a hot-water cylinder turns on in response to a cooling thermostat, but could easily be turned on a little earlier or later without significant side effects to help smooth out a peak in demand. Refrigeration and space-heating are similar "discretionary" activities. Any of these longer-term discretionary loads could be temporarily suspended in favor of shorter term imperatives such as boiling a kettle or heating dinner in the microwave. Further, provided with the relevant information about instantaneous cost, users may choose, for example, not to turn on their washing machine until prices drop later in the day. Some of these decisions might be automated (with consumer configurable parameters), while others may be one-off consumer initiated actions. Either way, it is an informed decision.

Like all infrastructure, electricity cost is governed by peak demand and utilization. The economic cost of electricity to a nation is determined by the size and frequency of large investments made to cover peak loads, and the resulting underutilization of the assets created. The environmental cost is also strongly determined by the pattern of electricity usage, because peak demand can exceed the capacity of generation facilities that use renewable resources. Thus this proposed transformational approach to load smoothing and matching by informed demandside management has the potential to yield very large benefits to an economy through deferred investment and reduced costs to all (not just domestic) consumers. Household energy consumption data [11] shows a typical domestic daily load variation (excluding 
nights) of around $70 \%$, suggesting that without overall reduction in consumption, peak demand could be reduced to $\sim 65 \%$ of its previous level, a reduction by $35 \%$ of the peak domestic demand, or around $12 \%$ of overall peak demand. Although this figure is a theoretical ideal, and although some of the potential is already offset by scheduling certain industrial loads in the domestic nighttime trough, experience with demand-side management, both manual [8] and automated [3], suggests that at a minimum, a reduction of $15 \%$ is achievable, equivalent to $5 \%$ of the overall peak demand.

A further benefit of this approach is the close linking of demandside load management with supply-side load manipulation. With the growth of non-deterministic energy generation (wind, tide, solar, etc), energy suppliers need ways to increase consumption at times of plentiful supply, and reduce consumption at times of lower supply. Using dynamic pricing in conjunction with informed demand-side management provides a simple means to facilitate this end. The proposed solution also allows for the possibility that consumers might permit their power company to directly control some usage, in exchange for price consideration. This is similar in its effect to ripple control, but the fine-grained interaction allows smooth switching actions, with precise magnitudes. For example, a power company can 'dump' a sudden surge of energy from a wind farm into their community's water heaters.

\section{COMPONENT TECHNOLOGIES}

There are three main threads to the IDSLM project

1. The large-scale fine-grained simulation of domestic electricity consumption, to gain a better understanding of the contributions of individual household savings and demand smoothing to reduction of peak demand at a regional and national level.

2. An exploration of means (through information visualization) to better convey to users/consumers instantaneous and accumulated data about their energy consumption, its cost and impact, and the choices available to them.

3. The development of fine-grained low-impact monitoring and control techniques appropriate to be applied at the individual appliance level. The ability to retro-fit such facilities to existing household wiring and to existing appliances is as important as de novo installations.

This paper is concerned principally with the second of these activities, but to appreciate the requirements and motivation for the visualizations, it is important to have a broader understanding of the context in which they are used.

\subsection{Domestic Electricity Simulation}

The foundation thesis, that a reduction in overall peak demand can be achieved through individual household load micromanagement without seriously impacting quality of life, is being extensively tested and explored through a comprehensive computer simulation model built around existing energy consumption data. This data provides detailed information on domestic energy use from a range of households representing a diversity of socio-economic groups, over an extended time period. The simulation reaches down to the individual appliance level, and when complete, will include environmental "comfort" parameters, and will enable the exploration of the effect of informed demand-side load management influenced by supplyside contextual parameters such as cost, availability, time of day, variation in local industrial loads, and the influence of nondeterministic alternative power sources, such as wind farms and tidal installations. The simulation is sufficiently fine-grained to allow exploration of patterns of use and control of individual appliances and devices, while at the same time allowing aggregation up to household, community and national levels.

The simulation will also explore the extent to which rate of takeup of demand-side load management influences its economic viability; what percentage of households need to be converted before there is a measurable national impact, and would a regional roll-out work?

\subsection{Monitoring and Control}

There has been considerable experimentation with 'smart metering' as a means of helping consumers to manage their electricity usage (for example [3,8]). There are a variety of smart metering technologies in use; capabilities provided may include bidirectional communication between home and power company, allowing variable (time-of-day or load related) pricing, precise billing and provision of detailed information to customers about usage patterns, and a display system to show customers current price and usage, sometimes including information about environmental impact. Unfortunately, many so-called smart metering systems provide no more than remote metering, and the majority of current systems measure only overall household usage; the consumer is left to guess which appliances are responsible for that usage. Most households consume electricity for a diverse range of purposes, including cooking, water-heating, air-conditioning, refrigerator, laundry, lighting, computers, games consoles, spa pools, and charging batteries in a host of electronic vade mecums. There are many opportunities for power saving and peak load management, but the task is difficult without the ability to monitor and control power usage at the individual appliance level.

For this part of the IDSLM project, a prototype fine-grained monitoring and control facility has been developed, and is currently under full evaluation in a domestic setting. Distributed monitoring and control is carried out by plug overlays - our device (called an e-point) plugs into a power socket; an appliance plugs into an e-point (Figure 1). The device, like many others on the market, measures power consumption (voltage, current and power factor), but is also capable of bidirectional communication with a base station ${ }^{1}$ using a network-over-power-line technology [14]. As a consequence we can provide real-time reporting and full remote control and intervention at the point of consumption. Remote control can be from rule interpretation on the base device, or can be manual. The e-point device has a roughly similar complexity to a miniature fluorescent light bulb. It can be easily fitted into an existing house without modification to wiring. Installation of an individual device offers immediate benefits, scaling as additional devices are added. Deployment is therefore straightforward and can be staged in any manner that is convenient. Immediate development planned includes assessing control strategies on a local and global scale, particularly with

\footnotetext{
${ }^{1}$ At the present time this base-station is a stand-alone device, but a USB interface to the home computer is under development.
} 
regard to system stability and real economic and efficiency impacts.

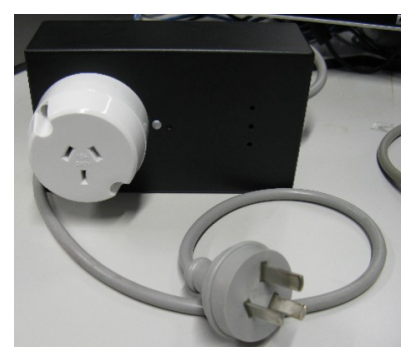

(a)

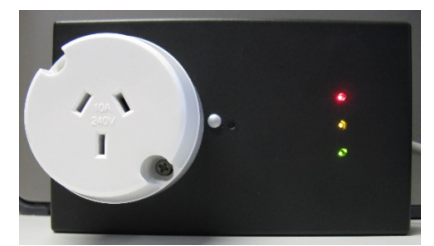

(b)
Figure 1: (a) An e-point device for monitoring and controlling an individual appliance, and (b) a view showing its ambient "traffic-light" display

In operation, for example, a collection of e-points and a controller can be set up to ensure that instantaneous power consumption never exceeds a pre-set maximum, by temporarily turning off lower priority "discretionary" appliances (eg water heating) when higher priority short-term "imperative" appliances (eg espresso machine) are activated as required to achieve this goal. In another situation, the e-point may delay the activation of a particular appliance because the current electricity spot-price is too high. In either case, the e-point includes provision for the user to manually override these settings. Because e-points are low-cost, fully distributed, and almost unlimited in number for any given installation, they not only enable automated and/or remote control at each point of consumption, but also provide fine-grained reporting of power consumption in real-time with full history tracking at the base station.

\section{VISUALISING POWER AND ENERGY}

For full consumer engagement with IDSLM, and for the effective utilization of the potential that it provides, it is essential that upto-date and relevant power usage information is readily available. Three issues are fundamental to delivering this information:

1. The consumer's understanding (and mental model) of power and energy concepts;

2. Appropriate visualizations for effectively conveying relevant aspects of this information;

3. The appropriate physical form and placement of these visualizations.

Work is in progress on each of these issues.

\subsection{Mental Models of Power and Energy}

Although most people are familiar and comfortable with the relationship between, and purposes of, the speedometer and odometer of a car, they are generally less at ease with the relationship between electrical power and electrical energy, metrics which bear an analogous relationship with one-another. Even in those situations where these measures are understood, the fact that most appliances associated with heating or cooling are thermostatically controlled, so that their instantaneous consumption is apparently erratic, is an added confusion. Complicating this matter is the fact that at present, financial incentives to understand and act on energy saving strategies are weak [4]. In response to frequent exhortations to save energy by reducing heating/cooling or taking shorter showers, Backlund et al [2] suggest: "Saving energy is therefore regarded as something negative that makes life less comfortable and enjoyable, and the means of displaying or controlling energy use are technically centered and aesthetically immature".

The IDSLM project is attempting to redress both issues expressed by this not unreasonable sentiment. The controls enabled by the technology $\$ 2.2$ can achieve load smoothing without noticeable impact on comfort and quality of life, which we are demonstrating through the simulation described in $\$ 2.1$. Through a survey currently in progress we aim to establish convergence between users' understanding, their motivations (is it really saving the planet, or is it their bank balance?) and the visualizations we use to convey relevant information to them, to provide a more household/user/activity focused front to the technology.

\subsection{Specific and Ambient Visualizations and their Placement}

The effective implementation of the IDSLM principles requires that energy consumption and potential activity impact information be readily (and unobtrusively) available, at the point of consumption, activity or repose. Acceptability of home notification schemes [16], and a diverse and innovative range of ambient energy-related displays or indicators [2, 15], have been discussed elsewhere. Potential ambient indicators include poweraware appliance cords [10,13], a form-changing lamp [2], and an indicator of hot-water usage in the shower [12]. Composite global household and community energy data representations have also been described by others $[5,9]$.

At this stage we have focused on two specific requirements; the need for localized information at the point of consumption, and the need for distributed global but detailed household information, not necessarily at a central location. Although awareness and consciousness-raising is important, our visualizations are required to convey specific information.

The e-point itself provides limited information at the point of consumption. The "traffic-light" display (Figure 1b) can be utilized in a variety of ways. As an indicator prior to activation, the display can be utilized to show potential impact; green-OK, red-not a good idea right now. The display can also show a response to an attempt at manual activation; green-activated; rednot activated; orange-not activated but can be overridden; flashing orange-appliance will be activated later. The e-point also has a speech output facility, so that the visual indicators can be supplemented by a brief explanatory spoken phrase [14]; no memorizing of the traffic light codes is required.

Figure 2 shows three specific visualizations of global household information. A study is currently underway to establish the effectiveness of each of these display forms, and their most appropriate location. Figure 2(a) shows a three-parameter display; current power consumption (arrow length), today's power history (red polar plot on time-of-day circle), and today's current total energy consumption (the area of the central blue circle). This visualization is likely to be centrally located rather than distributed; the home computer or a pop-up window on the TV are placements being evaluated. 
Figure 2(b) shows the contribution to the current power consumption of various appliances, and anticipates the impact of activating a further appliance, the espresso machine. An implication of this particular display is that this action will take the total instantaneous power consumption over some predetermined limit, which may move the household into a higher charging rate. However, it also shows that temporarily turning off the hot-water heater or the iron would avoid this problem. Such information should be readily available near the point of activity, so a number of specialized displays may be required distributed around the household.

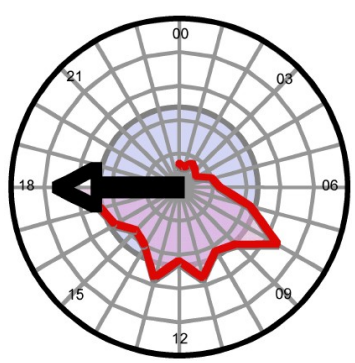

(a)

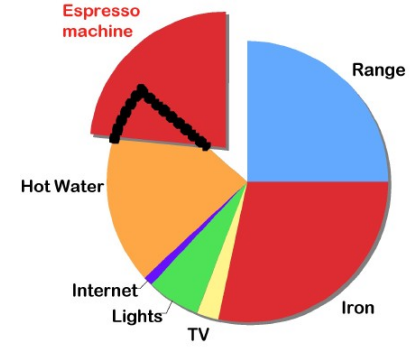

(b)

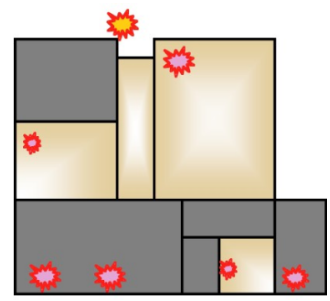

(c)

Figure 2: Three visualization forms being assessed

Figure 2(c) is a display which indicates on a plan of the house where, and to what extent, electricity consumption is currently occurring, showing, for example, that someone may have inadvertently left the light on in the bathroom, or have forgotten to turn off the stove after heating their dinner.

\section{PROGRESS AND CONCLUSIONS}

In this paper we have described work in progress on a comprehensive project to develop informed demand-side load management techniques to support and promote energy efficiency and economy in the residential/household sector. The necessary technological infrastructure has been developed; it is the embedding of this infrastructure into the household culture, and the full assessment of its impact at the personal, community and national levels which is currently in train. Acceptable and effective information visualization techniques are vitally important to this endeavor.

\section{REFERENCES}

[1] Apperley, M.D. and Rogers, W. 2009. Informed demand-side electricity load management. NERI 2009 On-line Proceedings. http://www.neri.org.nz/pdfs/conference09/Apperley.pdf [27 October, 2009]
[2] Backlund, S., Gyllenswärd, M., Gustafsson, A., Hjelm, S.I., Mazé, R., and Redström, J. 2006. STATIC! The aesthetics of energy in everyday things. Paper presented at the DRS Wonderground conference, 1-4 November, 2006. http://eprints.sics.se/2608/01/WonderSTATIC.pdf [31 December, 2009].

[3] Caterinicchia, D. 2008. Energy use cut if savings are apparent, study finds, 13 January. http://www.seattlepi.com/business/347150 electricitybill14.h tml [27 October 2009].

[4] Chetty, M., Bernheim Brush, A.J., Myers, B.R., and Johns, P. 2009. It's not easy being green: understanding home computer power management. CHI Conference on Human Factors in Computing Systems, Boston, MA, USA, 10331042.

[5] DEHEMS Digital Environment Home Energy Management System. http://www.dehems.com/ [31 December, 2009]

[6] EIA Annual Energy Review 2008. http://www.eia.doe.gov/emeu/aer/consump.html [30 October, 2009]

[7] Electricity Demand-side Management, Treasury Report, October 2005. Available as http://www.treasury.govt.nz/electricity/edm/edm-oct05.pdf [31 December, 2009]

[8] Frew, W. 2006. Smart metering cuts costs, 28 January. http://www.smh.com.au/articles/2006/01/27/1138319450051. html [27 October, 2009].

[9] Google PowerMeter. http://www.google.org/powermeter/ [30 November, 2009]

[10] Gustafsson, A. and Gyllensward, M. 2005. The PowerAware Cord: Energy Awareness through Ambient Information Display. CHI Conference on Human Factors in Computing Systems, Portland, OR, USA, 1423-1426.

[11] Isaacs N.P., Camilleri M., French L., Pollard A., SavilleSmith K., Fraser R., Rossouw P. \& Jowett J.H. 2006. Energy Use in New Zealand Households: Report on the Year 10 Analysis for the Household Energy End-use Project (HEEP). Judgeford, Porirua: BRANZ Ltd (Study Report 155)

[12] Kappel, K. and Grechenig, T. 2009. "show-me": water consumption at a glance to promote water conservation in the shower. Proc $4^{\text {th }}$ International Conference on Persuasive Technology, Claremont, CA, USA. Article \#26.

[13] Kim, Ju-Whan., Kim, Yun-Kyung., and Nam, Tek-Jin. 2009. The ténéré: design for supporting energy conservation behaviours. CHI Conference on Human Factors in Computing Systems, Boston, MA, USA, 2643-2646.

[14] Monigatti, P. 2009. Design and implementation of an electricity management system. COMP520 Project Report, University of Waikato, 2009.

[15] Pierce, J., Odom, W., and Blevis, E. 2008. Energy aware dwelling: a critical survey of interaction design for ecovisualisations. Proc OZCHI 2008, 1-8.

[16] Vastenburg, M.H., Keyson, D.V., and de Ridder, H. 2008. Considerate home notification systems: a field study of acceptability of notifications in the home. Personal and Ubiquitous Computing (2008) 12:555-566. 